\title{
Correction: Prednisolone and acupuncture in Bell's palsy: study protocol for a randomized, controlled trial
}

Feng Xia ${ }^{1}$, Junliang Han ${ }^{1}$, Xuedong Liư ${ }^{1}$, Jingcun Wang ${ }^{1}$, Zhao Jiang ${ }^{1}$, Kangjun Wang ${ }^{2}$, Songdi $\mathrm{Wu}^{3}$ and Gang Zhao ${ }^{*}$

\section{Correction}

Following publication of this protocol [1], it was brought to the Editors' attention in May 2014 that design of the study has been changed from a randomized controlled trial to a non-randomized study, and so will no longer follow the published protocol. For more information on the updated design and conduct of the study, please contact the corresponding author.

\section{Author details}

${ }^{1}$ Department of Neurology, Xijing Hospital, The Fourth Military Medical University, Xi'an, Shaanxi, China. ${ }^{2}$ Department of Neurology, Central Hospital, Hanzhong, Shaanxi, China. ${ }^{3}$ Department of Neurology, The First Hospital, Xi'an, Shaanxi, China.

Received: 9 July 2014 Accepted: 31 July 2014

Published: 8 August 2014

\section{References}

1. Xia F, Han J, Liu X, Wang J, Jiang Z, Wang K, Wu S, Zhao G: Prednisolone and acupuncture in Bell's palsy: study protocol for a randomized, controlled trial. Trials 2011, 12:158.

doi:10.1186/1745-6215-15-315

Cite this article as: Xia et al:: Correction: Prednisolone and acupuncture

in Bell's palsy: study protocol for a randomized, controlled trial. Trials 2014 15:315.

\footnotetext{
* Correspondence: zhaogang@fmmu.edu.cn

${ }^{1}$ Department of Neurology, Xijing Hospital, The Fourth Military Medical

University, Xi'an, Shaanxi, China
} 